\title{
Hybrid Evolutionary Strategy and Simulated Annealing Algorithms for Integrated Process Planning, Scheduling and Due-Date Assignment Problem
}

\author{
Halil İbrahim Demir ${ }^{1}$, Rakesh Kumar Phanden², Abdullah Kökçam³ ${ }^{3}$ Burak Erkayman ${ }^{4}$, Caner Erden ${ }^{5 *}$ \\ ${ }^{1}$ Industrial Engineering Department, Sakarya University, Sakarya, Turkey, hidemir@sakarya.edu.tr \\ ${ }^{2}$ Department of Mechanical Engineering, Amity University, Uttar Pradesh Noida, India, rkphanden@amity.edu iD \\ ${ }^{3}$ Industrial Engineering Department, Sakarya University, Sakarya, Turkey, akokcam@sakarya.edu.tr \\ ${ }^{4}$ Industrial Engineering Department, Atatürk University, Erzurum, Turkey, erkayman@atauni.edu.tr \\ ${ }^{5}$ Faculty of Applied Sciences, Sakarya University of Applied Sciences, Sakarya, Turkey cerden@ subu.edu.tr \\ Research Paper \\ Arrival Date: 04.07.2020 \\ Accepted Date: 21.11 .2020
}

\begin{abstract}
Although integrated process planning and scheduling (IPPS) problem is studied extensively as scheduling with due-date assignment problem (SWDDA) in the literature, there are only a few studies on integration of these three manufacturing functions which are process planning, scheduling, and due-date assignment. Since outputs of upper stream functions effect downstream functions and higher integration gives a better global performance, it is better to integrate these three functions. In this study integration of process planning and earliest due-date scheduling (EDD) with due-date assignment is studied using hybrid evolutionary strategies (RS/ES) and hybrid simulated annealing algorithms (RS/SA). Ordinary solutions (OS), random search (RS) solutions, evolutionary strategies (ES) solutions, and simulated annealing (SA) solutions are compared with each other and hybrid solutions of ES and SA, with RS. According to the results, higher integration found better and best results are obtained with the highest integration level. ES and SA methods gave better results compared to the RS and OS, and RS/ES and RS/SA techniques were found promising search techniques.
\end{abstract}

Keywords: Process planning, scheduling, due-date assignment, hybrid evolutionary strategies, hybrid simulated annealing, random search

\section{INTRODUCTION}

Process planning, scheduling, and due-date assignment are three primary manufacturing functions in a job shop environment, which directly affect each other. Integration is a necessity to improve overall performance. There are many studies on integration of the first pair (Integrated Process Planning and Scheduling - IPPS) and second pair (Scheduling With Due-Date Assignment - SWDDA) of these functions. However, there are a few studies on integration of all three functions (Integrated Process Planning, Scheduling, and Due-Date Assignment - IPPSDDA).

There are comprehensive literature surveys on IPPS problem such as Tan and Khosnevis [1], Li et al. [2] and Phanden et al. [3]. As an example of studies on IPPS problem Morad and
Zalzala [4], Tan and Khoshnevis [5], Guo et al. [6], Baykasoğlu ve Özbakır [7], Leung et al. [8], Phanden et al. [9], Zhang and Wong [10] can be given.

Due-dates can be determined internally in which best dates can be investigated or externally in which they cannot be changed. There are two aspects of determining due-dates which are delivery reliability and speed [11]. Delivery reliability is an indicator that shows consistency in meeting orders as promised. Delivery speed is an ability to deliver orders with short lead times.

A comprehensive literature survey on SWDDA can be found in Gordon et al. [12]. Recent SWDDA studies can be given as Yin et al. [13-15], Iranpoor et al. [16]. Following works can be given as studies on Scheduling With Due-Window Assignment (SWDWA) problem; and Yang et al. [17]. Some

* CorrespondingAuthor: Faculty of Applied Sciences, Sakarya University of Applied Sciences, Sakarya, Turkey cerden@subu.edu.tr

This article is extended from the paper titled "Solving Process Planning and Earliest Due Date Scheduling with Due Date Assignment Concurrently Using Hybrid Evolutionary Strategies and Hybrid Simulated Annealing Algorithms" published in the proceedings of the proceedings of "10th International Symposium on Intelligent Manufacturing and Service Systems". 
of the works on the IPPSDDA problem can be given as Demir and Taskin [18], Demir and Erden [19]-[21], [21], [22].

The main focus of scheduling problems involves due-dates. A job is expected to be finished before its due-date in a conventional production system. Unlike this, in Just in Time (JIT) production system a job is to be finished exactly on its due-date. Instead of assigning due-dates, a due window is tried to be assigned in recent studies in which research is shifted from SWDDA to SWDWA.

It is not desired to deliver orders later than its due-date. On the other hand, it is also not desired to produce early due to working capital and inventory holding costs. In order to improve performance measure earliness, tardiness and duedate related costs are all penalized in this study.

Merely, scheduling function is in the NP-Hard problem class. An integrated problem is far more difficult to solve. Exact solutions can be found for small problems but as problem size increases it is not possible to find exact solutions in a reasonable time. At this point heuristic methods are more suitable.

Planning is a timely decision that has to be determined in a certain time, otherwise, there is no value of a plan which is no longer valid. To overcome this problem instead of using exact solution methods heuristics are indeed very useful. In this research evolutionary strategies (ES), simulated annealing (SA) and their random hybrids (RS/ES and RS/SA) are utilized. Results of these meta-heuristics are compared with each other and also compared with random search (RS) and initial ordinary solution (OS).

The remaining of this paper is organized as follows: definition of the problem is given in section 2, solution methods and integration levels are given in section 3, experimentation is given in section 4 , and the conclusion is given in the last section.

\section{PROBLEM DEFINITION}

In this study integration of process planning, scheduling and due-date assignment functions are considered. Problem is represented as a chromosome with $(n+2)$ genes given in Figure 1. First two genes are used to represent due-date assignment and dispatching rules, respectively. Rest of the genes (n) represents the route of jobs. Effect of first two genes on a solution is higher than other genes which affects route of a single job. Thus, they have been found as dominant genes and given higher probability to be selected by mutation operator.

Eight different sized shop floors are considered which are given in Table 1. The first four problems have five routes for each job to select from, the last four problems have three routes for each job. As an example, the first shop floor has 5 machines, 25 jobs, and 10 operations for each job.

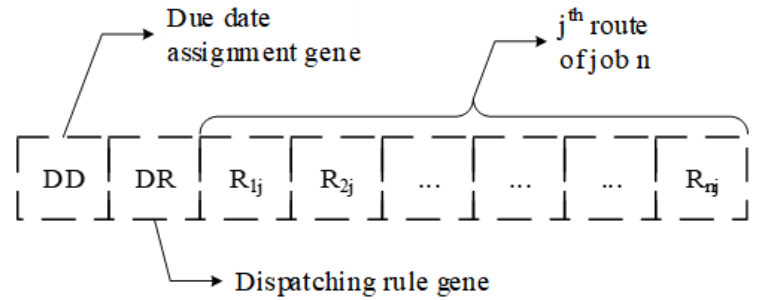

Figure 1. Sample chromosome

Table 1. Shop Floors

\begin{tabular}{|l|l|l|l|l|l|l|l|l|}
\hline Shop floor & $\mathbf{1}$ & $\mathbf{2}$ & $\mathbf{3}$ & $\mathbf{4}$ & $\mathbf{5}$ & $\mathbf{6}$ & $\mathbf{7}$ & $\mathbf{8}$ \\
\hline \# of machines & 5 & 10 & 15 & 20 & 25 & 30 & 35 & 40 \\
\hline \# of jobs & 25 & 50 & 75 & 100 & 125 & 150 & 175 & 200 \\
\hline \# of routes & \multicolumn{1}{|c|}{5} & \multicolumn{7}{|c|}{3} \\
\hline \# of operations per job & \multicolumn{10}{|c|}{10} \\
\hline
\end{tabular}

Three types of machine groups are defined to represent the technology and capability of machines. High technology machines are relatively fast, average machines are faster than old ones, and old machines are the slowest. The processing time of each operation is calculated according to the machine group it belongs given in Table 2. For example, processing times of machine group 1 are calculated according to normal distribution with a mean of 10 and a standard deviation of 5 . Each route has different probabilities to choose machine groups which are also given in Table 2 . For example, route 1 has probabilities of $0.8,0.1$, and 0.1 to select machine groups 1,2 , and 3, respectively for shop floors $1,2,3$, and 4 .

Table 2. Probability of machine group selection based on routes

\begin{tabular}{|c|c|c|l|l|l|l|l|}
\hline $\begin{array}{c}\text { Shop } \\
\text { Floor }\end{array}$ & $\begin{array}{c}\text { Machine } \\
\text { Group }\end{array}$ & $\begin{array}{c}\text { Processing } \\
\text { Times }\end{array}$ & Route1 & Route2 & Route3 & Route4 & Route5 \\
\hline \multirow{3}{*}{$\mathbf{1 , 2 , 3 , 4}$} & $\mathbf{1}$ & $\lfloor(10+z * 5)\rfloor$ & 0.8 & 0.6 & 0.33 & 0.2 & 0.1 \\
\cline { 2 - 8 } & $\mathbf{2}$ & $\lfloor(12+z * 6)\rfloor$ & 0.1 & 0.25 & 0.33 & 0.3 & 0.2 \\
\cline { 2 - 8 } & $\mathbf{3}$ & $\lfloor(14+z * 7)\rfloor$ & 0.1 & 0.15 & 0.34 & 0.5 & 0.7 \\
\hline \multirow{3}{*}{$\mathbf{5 , 6 , 7 , 8}$} & $\mathbf{1}$ & $\lfloor(10+z * 5)\rfloor$ & 0.7 & 0.33 & 0.2 & N/A & N/A \\
\cline { 2 - 8 } & $\mathbf{2}$ & $\lfloor(12+z * 6)\rfloor$ & 0.2 & 0.33 & 0.2 & N/A & N/A \\
\cline { 2 - 8 } & $\mathbf{3}$ & $\lfloor(14+z * 7)\rfloor$ & 0.1 & 0.34 & 0.6 & N/A & N/A \\
\hline N/A: Not available
\end{tabular}

Due-date assignment is made with the first gene according to the RDM and DUE rules given in Table 3 and explained in Appendix A. DUE rule has four different options, which are TWK, SLK, PPW, and NOP. With different multipliers and constants, 18 different rules are used in DUE.

Table 3. Due-date assignment rules

\begin{tabular}{|c|c|l|l|}
\hline Method & $\begin{array}{c}\text { Multiplier } \\
\left(\boldsymbol{t} w \boldsymbol{k}_{\boldsymbol{x}}, \boldsymbol{p}_{\boldsymbol{x}}\right)\end{array}$ & Constant $\left(\boldsymbol{q}_{\boldsymbol{x}}\right)$ & \multicolumn{1}{|c|}{ Rule no } \\
\hline $\begin{array}{c}\text { Total Work } \\
\text { (TWK) }\end{array}$ & $\begin{array}{l}t w k_{x} \\
=t w k_{1}, t w k_{2}, t w k_{3}\end{array}$ & & $1,2,3$ \\
\hline Slack (SLK) & & $q_{x}=q_{1}, q_{2}, q_{3}$ & $4,5,6$ \\
\hline $\begin{array}{c}\text { Processing Plus } \\
\text { Wait (PPW) }\end{array}$ & $\begin{array}{l}t w k_{x} \\
=t w k_{1}, t w k_{2}, t w k_{3}\end{array}$ & $q_{x}=q_{1}, q_{2}, q_{3}$ & $\begin{array}{l}7,8,9,10,11,12, \\
13,14,15\end{array}$ \\
\hline $\begin{array}{c}\text { Number of } \\
\text { Operations (NOP) }\end{array}$ & $p_{x}=p_{1}, p_{2}, p_{3}$ & & $16,17,18$ \\
\hline $\begin{array}{c}\text { Random Due } \\
\text { Assign (RDM) }\end{array}$ & & & 19 \\
\hline
\end{tabular}


Dispatching is made with the second gene according to Earliest Due-Date (EDD) and Service in Random order (SIRO) rules. A job among waiting jobs is selected randomly to be processed in SIRO.

A working day is assumed as one shift with 8 hours (480 minutes). Tardiness, earliness and due-dates are penalized as it contributes to making more realistic plans. The performance measure is to minimize the costs resulting from these. The proportion of these costs are penalized with different constants as given in Eq. (1), (2), and (3). Tardiness and earliness are also penalized with a fixed cost. Tardiness is punished more than others. The penalty of a job and the total penalty is given in Eq. (4) and (5), respectively.

$$
\begin{aligned}
& \text { Penalty for Due }- \text { Dates }(P D)=8 *\left(\frac{\text { DueDate }}{480}\right) \\
& \text { Penalty for earliness }(\mathrm{PE})=5+4 *\left(\frac{\mathrm{E}}{480}\right) \\
& \text { Penalty for tardiness }(P T)=10+12 *\left(\frac{T}{480}\right) \\
& \text { Penalty }(j)=P D+P E+P T \\
& \text { Total Penalty }=\sum_{j} \text { Penalty }(j)
\end{aligned}
$$

\section{SOLUTION METHODS AND INTEGRATION LEVELS}

OS, RS, ES, SA, RS/ES, and RS/SA methods are used to solve the IPPSDDA problem. To be fair among different methods their population size and iteration numbers are equalized. A number of iterations applied are given in Table 4.

Table 4. Number of iterations applied

\begin{tabular}{|l|l|c|l|c|l|l|c|}
\hline & RS & SA & \multicolumn{2}{|c|}{ RS-SA Hybrid } & \multicolumn{2}{|c|}{ ES } & $\begin{array}{c}\text { RS-ES } \\
\text { Hybrid }\end{array}$ \\
\hline SF & $\begin{array}{c}\text { RS } \\
\text { Iter. }\end{array}$ & $\begin{array}{c}\text { SA } \\
\text { Iter. }\end{array}$ & $\begin{array}{c}\text { RS } \\
\text { Iter. }\end{array}$ & $\begin{array}{c}\text { SA } \\
\text { Iter. }\end{array}$ & $\begin{array}{c}\text { ES } \\
\text { Iter. }\end{array}$ & $\begin{array}{c}\text { RS } \\
\text { Iter. }\end{array}$ & $\begin{array}{c}\text { ES } \\
\text { Iter. }\end{array}$ \\
\hline $\mathbf{1 , 2}$ & 200 & 2000 & 100 & 1900 & 200 & 10 & 190 \\
\hline $\mathbf{3 , 4}$ & 150 & 1500 & 75 & 1425 & 150 & 8 & 142 \\
\hline $\mathbf{5 , 6}$ & 100 & 1000 & 50 & 950 & 100 & 5 & 95 \\
\hline $\mathbf{7 , 8}$ & 50 & 500 & 25 & 475 & 50 & 3 & 47 \\
\hline
\end{tabular}

Solution methods are shortly explained as follows:

Ordinary Solution (OS): Randomly produced initial chromosome in which one of the random chromosomes generated in the beginning is an ordinary solution. This is the worse solution method compared to the other meta-heuristic methods.

Random Search (RS): RS is an undirected search method that generates 10 new chromosomes randomly in each iteration. The best 10 chromosomes are selected from the new population and the previous population. RS is better than OS. Marginal improvements are very high in the beginning but sharply reduces as the iterations go on.

Simulated Annealing (SA): SA is utilized in this study with a single chromosome in each iteration. Thus, more iterations are made with SA to be fair with other methods.

Hybrid Simulated Annealing (RS/SA): With this hybrid method initial marginal benefits of undirected RS is combined with a directed search of SA. In this method, 5\% of total iterations are made with RS and the rest of the iterations are made with SA.

Evolutionary Strategies (ES): ES is an optimization method based on the ideas of evolution. ES differs from the genetic algorithm (GA) by operator types. GA uses both mutation and crossover operators, on the other hand, ES only uses mutation operator.

Hybrid Evolutionary Strategies (RS/ES): With this hybrid method initial marginal benefits of undirected RS is combined with a directed search of ES. In this method, 5\% of total iterations are made with RS and the rest of the iterations are made with ES.

Different integration levels of three production functions are utilized. There is no integration in the SIRO-RDM level. Process plan selection is made without considering scheduling and due-date assignment. Scheduling of jobs made randomly as due-dates. EDD scheduling with process plan selection is integrated in EDD-RDM level. But duedates are still randomly determined. In SIRO-DUE level duedate assignment is integrated to process planning however jobs are scheduled randomly. EDD-DUE is the fully integrated level in which process planning is integrated with EDD dispatching and due-date assignment.

\section{EXPERIMENTATION}

IPPSDDA problem is coded with the $\mathrm{C}++$ language. Experiments are executed in a desktop computer with 64-bit Windows 10 operating system on a $3.1 \mathrm{GHz}$ Intel i5-2400 processor and $4 \mathrm{~GB}$ ram. Problems are compiled with Borland C++ 5.02 compiler. Mean CPU times of shop floors 1 to 8 are $14,82,163,312,233,348,239$, and 318 seconds, respectively.

There are 6 different methods and 4 different integration combinations, a total of 24 different solution combinations are calculated for each shop floor and summarized in Table 5 and Table 6. Results of highest integration combination (EDD-DUE) of shop floors 1-4 are given in Figure 2 (a,b,c,d) and shop floors 5-8 are given in Figure 3 (a,b,c,d), respectively. Similar conclusions can be made for different shop floors according to results. The performance of solutions gets better as the integration level increases. Search methods are superior compared to ordinary solutions. RS is the worst search solution compared to other methods. ES and RS/ES methods are the best amongst all methods. 
Table 5. Comparison of 24 solution combinations for the shop floors 1-4

\begin{tabular}{|c|c|c|c|c|c|c|c|c|c|c|c|c|c|}
\hline \multirow{2}{*}{$\begin{array}{c}\text { Level of } \\
\text { Integration } \\
\text { (Combination) }\end{array}$} & \multirow{2}{*}{ 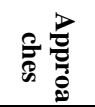 } & \multicolumn{3}{|c|}{ Shop Floor 1} & \multicolumn{3}{|c|}{ Shop Floor 2} & \multicolumn{3}{|c|}{ Shop Floor 3} & \multicolumn{3}{|c|}{ Shop Floor 4} \\
\hline & & Best & Avg. & Worst & Best & Avg. & Worst & Best & Avg. & Worst & Best & Avg. & Worst \\
\hline \multirow{6}{*}{ SIRO-RDM } & OS & 319 & 319 & 319 & 646 & 646 & 646 & 983 & 983 & 983 & 1309 & 1309 & 1309 \\
\hline & RS & 265 & 272 & 276 & 586 & 598 & 606 & 890 & 899 & 906 & 1269 & 1278 & 1285 \\
\hline & SA & 269 & 273 & 275 & 543 & 553 & 557 & 853 & 862 & 870 & 1226 & 1234 & 1240 \\
\hline & RS/SA & 253 & 256 & 258 & 562 & 566 & 568 & 863 & 873 & 880 & 1223 & 1234 & 1238 \\
\hline & ES & 246 & 252 & 254 & 546 & 552 & 556 & 833 & 842 & 846 & 1197 & 1204 & 1210 \\
\hline & RS/ES & 240 & 248 & 251 & 545 & 548 & 551 & 837 & 851 & 857 & 1207 & 1216 & 1222 \\
\hline \multirow{6}{*}{ EDD-RDM } & OS & 269 & 269 & 269 & 558 & 558 & 558 & 835 & 835 & 835 & 1187 & 1187 & 1187 \\
\hline & RS & 219 & 228 & 234 & 513 & 539 & 547 & 788 & 796 & 802 & 1156 & 1172 & 1183 \\
\hline & SA & 197 & 201 & 204 & 472 & 482 & 486 & 753 & 758 & 762 & 1104 & 1115 & 1123 \\
\hline & RS/SA & 198 & 203 & 205 & 463 & 480 & 484 & 746 & 751 & 755 & 1089 & 1102 & 1105 \\
\hline & ES & 189 & 194 & 196 & 469 & 473 & 476 & 719 & 727 & 734 & 1038 & 1060 & 1068 \\
\hline & RS/ES & 201 & 204 & 207 & 446 & 454 & 462 & 716 & 722 & 725 & 1076 & 1080 & 1083 \\
\hline \multirow{6}{*}{ SIRO-DUE } & OS & 347 & 347 & 347 & 730 & 730 & 730 & 1087 & 1087 & 1087 & 1504 & 1504 & 1504 \\
\hline & RS & 258 & 264 & 270 & 559 & 581 & 592 & 825 & 845 & 859 & 1182 & 1213 & 1227 \\
\hline & SA & 243 & 249 & 252 & 512 & 524 & 530 & 804 & 814 & 821 & 1138 & 1148 & 1154 \\
\hline & RS/SA & 238 & 242 & 245 & 510 & 526 & 533 & 802 & 815 & 821 & 1128 & 1144 & 1149 \\
\hline & ES & 221 & 232 & 237 & 498 & 510 & 514 & 776 & 781 & 789 & 1100 & 1115 & 1122 \\
\hline & RS/ES & 231 & 236 & 239 & 507 & 510 & 513 & 767 & 779 & 786 & 1120 & 1132 & 1140 \\
\hline \multirow{6}{*}{ EDD-DUE } & OS & 300 & 300 & 300 & 581 & 581 & 581 & 869 & 869 & 869 & 1272 & 1272 & 1272 \\
\hline & RS & 230 & 235 & 239 & 507 & 512 & 514 & 730 & 749 & 758 & 1064 & 1078 & 1083 \\
\hline & SA & 204 & 208 & 210 & 462 & 467 & 471 & 693 & 702 & 707 & 1005 & 1016 & 1021 \\
\hline & RS/SA & 210 & 215 & 217 & 449 & 460 & 465 & 667 & 685 & 689 & 1038 & 1041 & 1043 \\
\hline & ES & 206 & 210 & 212 & 441 & 448 & 451 & 672 & 680 & 683 & 987 & 993 & 997 \\
\hline & RS/ES & 205 & 208 & 210 & 434 & 440 & 443 & 665 & 671 & 673 & 976 & 985 & 989 \\
\hline
\end{tabular}

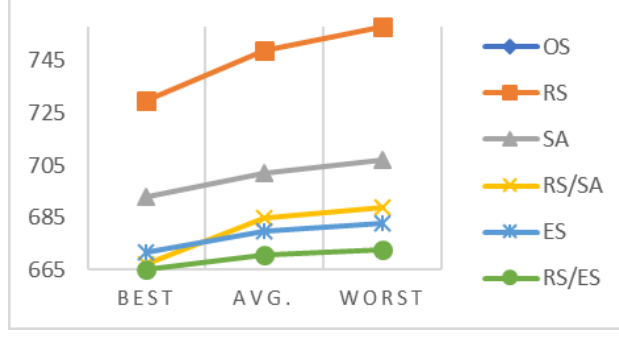

(a)

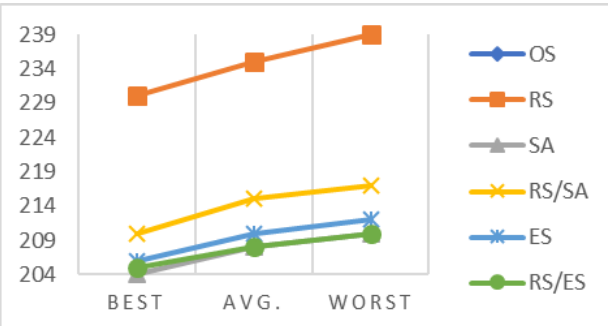

(c)

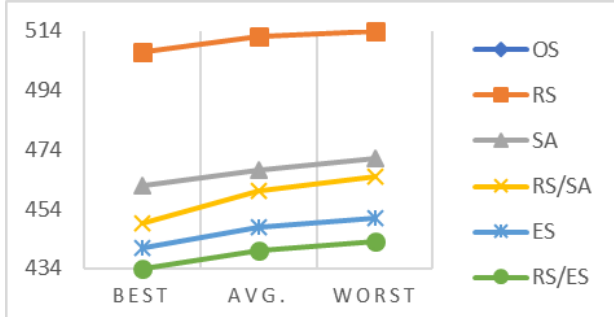

(b)

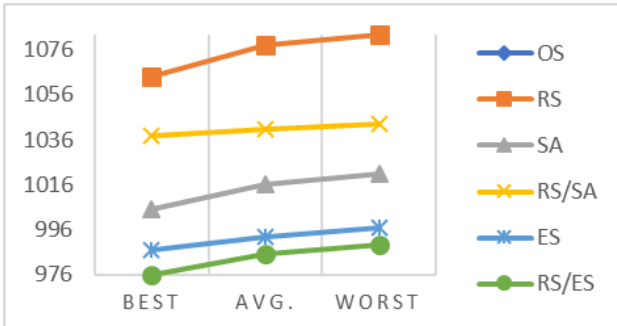

(d)

Figure 2. Performance comparisons of shop floors 1-4 
Table 6. Comparison of 24 solution combinations for the shop floors 5-8

\begin{tabular}{|c|c|c|c|c|c|c|c|c|c|c|c|c|c|}
\hline \multirow{2}{*}{$\begin{array}{c}\text { Level of } \\
\text { Integration } \\
\text { (Combination) }\end{array}$} & \multirow{2}{*}{ 胥胥 } & \multicolumn{3}{|c|}{ Shop Floor 5} & \multicolumn{3}{|c|}{ Shop Floor 6} & \multicolumn{3}{|c|}{ Shop Floor 7} & \multicolumn{3}{|c|}{ Shop Floor 8} \\
\hline & & Best & Avg. & Worst & Best & Avg. & Worst & Best & Avg. & Worst & Best & Avg. & Worst \\
\hline \multirow{6}{*}{ SIRO-RDM } & OS & 1831 & 1831 & 1831 & 2110 & 2110 & 2110 & 2154 & 2154 & 2154 & 2783 & 2783 & 2783 \\
\hline & RS & 1590 & 1632 & 1644 & 1914 & 1930 & 1944 & 2108 & 2154 & 2171 & 2659 & 2707 & 2719 \\
\hline & SA & 1608 & 1616 & 1624 & 1848 & 1866 & 1876 & 2104 & 2123 & 2138 & 2598 & 2618 & 2628 \\
\hline & RS/SA & 1562 & 1575 & 1582 & 1864 & 1879 & 1888 & 2070 & 2089 & 2105 & 2613 & 2626 & 2637 \\
\hline & ES & 1556 & 1569 & 1577 & 1840 & 1858 & 1867 & 2067 & 2092 & 2101 & 2585 & 2600 & 2606 \\
\hline & RS/ES & 1538 & 1558 & 1566 & 1860 & 1877 & 1884 & 2060 & 2085 & 2092 & 2624 & 2628 & 2635 \\
\hline \multirow{6}{*}{ EDD-RDM } & OS & 1622 & 1622 & 1622 & 1956 & 1956 & 1956 & 2039 & 2039 & 2039 & 2495 & 2495 & 2495 \\
\hline & RS & 1407 & 1423 & 1431 & 1713 & 1732 & 1745 & 1970 & 1985 & 1991 & 2453 & 2470 & 2481 \\
\hline & SA & 1332 & 1356 & 1366 & 1638 & 1655 & 1664 & 1879 & 1905 & 1915 & 2371 & 2387 & 2396 \\
\hline & RS/SA & 1353 & 1362 & 1366 & 1675 & 1683 & 1688 & 1901 & 1922 & 1936 & 2358 & 2376 & 2387 \\
\hline & ES & 1313 & 1319 & 1323 & 1610 & 1620 & 1624 & 1912 & 1925 & 1935 & 2362 & 2379 & 2387 \\
\hline & RS/ES & 1310 & 1333 & 1341 & 1614 & 1630 & 1636 & 1931 & 1936 & 1941 & 2332 & 2357 & 2367 \\
\hline \multirow{6}{*}{ SIRO-DUE } & OS & 2040 & 2040 & 2040 & 2344 & 2344 & 2344 & 2490 & 2490 & 2490 & 3124 & 3124 & 3124 \\
\hline & RS & 1479 & 1497 & 1514 & 1747 & 1771 & 1794 & 1975 & 2028 & 2059 & 2530 & 2578 & 2610 \\
\hline & SA & 1389 & 1410 & 1427 & 1713 & 1748 & 1764 & 1894 & 1932 & 1947 & 2390 & 2439 & 2459 \\
\hline & RS/SA & 1386 & 1414 & 1425 & 1687 & 1724 & 1744 & 1951 & 1974 & 1991 & 2427 & 2442 & 2455 \\
\hline & ES & 1405 & 1418 & 1425 & 1683 & 1694 & 1705 & 1910 & 1923 & 1930 & 2437 & 2478 & 2499 \\
\hline & RS/ES & 1407 & 1414 & 1419 & 1675 & 1695 & 1704 & 1925 & 1937 & 1945 & 2399 & 2431 & 2446 \\
\hline \multirow{6}{*}{ EDD-DUE } & OS & 1659 & 1659 & 1659 & 1935 & 1935 & 1935 & 2078 & 2078 & 2078 & 2656 & 2656 & 2656 \\
\hline & RS & 1283 & 1313 & 1325 & 1572 & 1595 & 1604 & 1774 & 1800 & 1818 & 2208 & 2261 & 2280 \\
\hline & SA & 1236 & 1249 & 1257 & 1524 & 1544 & 1553 & 1730 & 1750 & 1761 & 2185 & 2203 & 2214 \\
\hline & RS/SA & 1233 & 1251 & 1257 & 1516 & 1530 & 1536 & 1742 & 1758 & 1767 & 2148 & 2178 & 2197 \\
\hline & ES & 1233 & 1244 & 1250 & 1504 & 1512 & 1516 & 1712 & 1722 & 1728 & 2147 & 2160 & 2170 \\
\hline & RS/ES & 1239 & 1245 & 1249 & 1507 & 1510 & 1514 & 1712 & 1722 & 1729 & 2184 & 2197 & 2209 \\
\hline
\end{tabular}
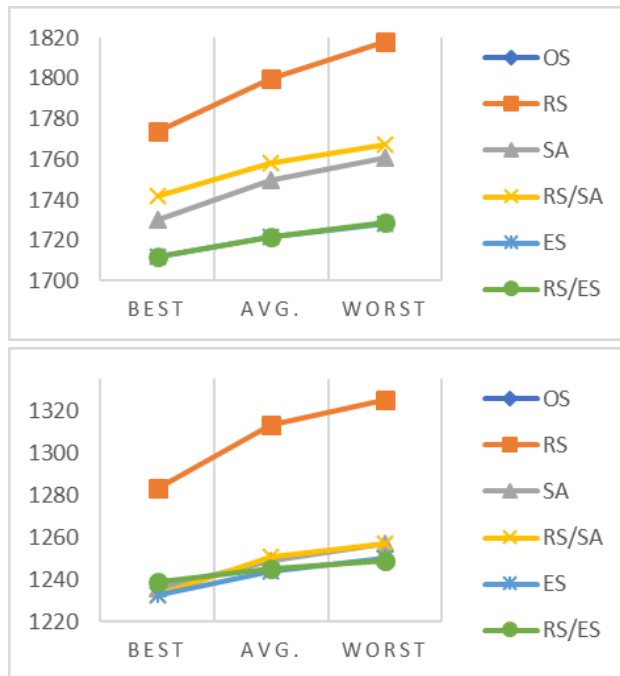

Figure 3. Performance comparisons of shop floors 5-8

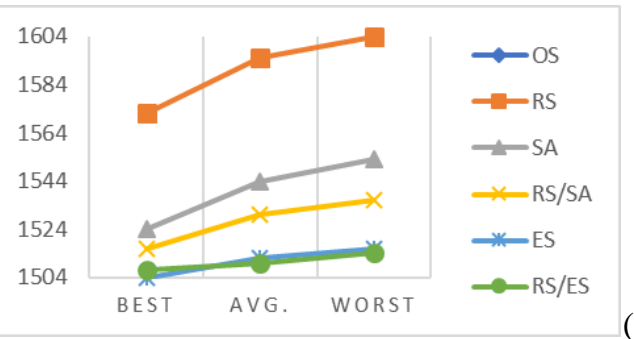

(b)

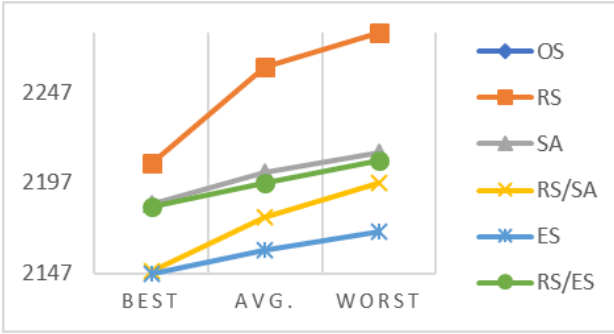

(d)

\section{CONCLUSIONS}

Process planning, scheduling, and due-date assignment are three important production functions that are traditionally solved separately. IPPS and SWDDA are studied in the literature and there are numerous works on them. On the other hand, the integration of all three functions is a relatively new subject. In this study, these functions are integrated and solved concurrently with different solution methods in which contributed to global performance.

Four different integration levels are tested with six solution method on eight different sized shop floor and compared with each other. While the unintegrated solution has the worst performance, a fully integrated solution has the best performance as expected. Results also show that ES and $\mathrm{RS} / \mathrm{ES}$ methods are best amongst others.

In the literature, studies are performed on IPPS and SWDDA and they only integrate two functions. But, in this study three functions are integrated to obtain higher global performance. The data set discussed in this study was created in a problemspecific structure and it was not right to compare with the data sets in the literature. As the studies on the integration of these three functions are performed more then there will be the possibility of benchmarking between studies.

Companies must find ways to survive in today's fierce competition. Using fewer resources to produce more qualified products is essential in this harsh environment. The results of this study encourage decision-makers to utilize 
their production functions as a whole and use suitable methods to solve them. The integration studies of manufacturing functions provide significant gains in terms of global optimization.

\section{REFERENCES}

[1] W. Tan and B. Khoshnevis, "Integration of process planning and scheduling-a review," Journal of Intelligent Manufacturing, vol. 11, no. 1, pp. 51-63, 2000, doi: 10.1023/A:1008952024606.

[2] X. Li, L. Gao, C. Zhang, and X. Shao, "A review on Integrated Process Planning and Scheduling," International Journal of Manufacturing Research, vol. 5, no. 2, pp. 161180, Jan. 2010.

[3] R. K. Phanden, A. Jain, and R. Verma, "Integration of process planning and scheduling: a state-of-the-art review," International Journal of Computer Integrated Manufacturing, vol. 24, no. 6, pp. 517-534, 2011.

[4] N. Morad and A. M. S. Zalzala, "Genetic algorithms in integrated process planning and scheduling," Journal of Intelligent Manufacturing, vol. 10, no. 2, pp. 169-179, 1999, doi: 10.1023/A:1008976720878.

[5] W. Tan and B. Khoshnevis, "A linearized polynomial mixed integer programming model for the integration of process planning and scheduling," J. intell. manuf., vol. 15, no. 5, pp. 593-605, 2004, doi: 10.1023/B:JIMS.0000037710.80847.b6.

[6] Y. W. Guo, W. D. Li, A. R. Mileham, and G. W. Owen, "Optimisation of integrated process planning and scheduling using a particle swarm optimisation approach," International Journal of Production Research, vol. 47, no. 14, pp. 3775-3796, 2009, doi: 10.1080/00207540701827905.

[7] A. Baykasoğlu and L. Özbakır, "A grammatical optimization approach for integrated process planning and scheduling," Journal of Intelligent Manufacturing, vol. 20, no. 2, pp. 211-221, 2009, doi: 10.1007/s10845-008-0223-0. [8] C. W. Leung, T. N. Wong, K.-L. L. Mak, and R. Y. K. Fung, "Integrated process planning and scheduling by an agent-based ant colony optimization," Computers and Industrial Engineering, vol. 59, no. 1, pp. 166-180, 2010, doi: 10.1016/j.cie.2009.09.003.

[9] R. R. K. Phanden, A. Jain, and R. Verma, "An approach for integration of process planning and scheduling," International Journal of Computer Idots, vol. 26, no. 4, pp. 284-302, Apr. 2013, doi: 10.1080/0951192X.2012.684721.

[10] L. Zhang and T. N. N. Wong, "An object-coding genetic algorithm for integrated process planning and scheduling," European Journal of Operational Research, vol. 244, no. 2, pp. 434-444, Jul. 2015, doi: 10.1016/j.ejor.2015.01.032.

[11] T. Hill, Production/operations management: text and cases. Prentice Hall, 1991.

[12] V. Gordon, J. M. Proth, and C. Chu, "Due date assignment and scheduling: SLK, TWK and other due date assignment models," Production Planning \& Control, vol. 13, no. 2, pp. 117-132, 2002, doi: 10.1080/09537280110069621.

[13] Y. Yin, S. R. Cheng, T. C. E. E. Cheng, C. C. Wu, and $\mathrm{W} . \mathrm{H}$. Wu, "Two-agent single-machine scheduling with assignable due dates," Applied Mathematics and Computation, vol. 219, no. 4, pp. 1674-1685, 2012, doi: 10.1016/j.amc.2012.08.008.

[14] Y. Yin, T. C. E. E. Cheng, D. Xu, and C.-C. C. Wu, "Common due date assignment and scheduling with a ratemodifying activity to minimize the due date, earliness, tardiness, holding, and batch delivery cost," Computers and Industrial Engineering, vol. 63, no. 1, pp. 223-234, 2012, doi: 10.1016/j.cie.2012.02.015.

[15] Y. Yin, M. Liu, T. C. E. Cheng, C. C. Wu, and S. R. Cheng, "Four single-machine scheduling problems involving due date determination decisions," Information Sciences, vol. 251, pp. 164-181, 2013, doi: 10.1016/j.ins.2013.06.035.

[16] M. Iranpoor, S. M. T. T. Fatemi Ghomi, and M. Zandieh, "Due-date assignment and machine scheduling in a low machine-rate situation with stochastic processing times," Computers and Operations Research, vol. 40, no. 4, pp. 1100-1108, 2013, doi: 10.1016/j.cor.2012.11.013.

[17] D. L. Yang, C. J. Lai, and S. J. Yang, "Scheduling problems with multiple due windows assignment and controllable processing times on a single machine," International Journal of Production Economics, vol. 150, pp. 96-103, 2014, doi: 10.1016/j.ijpe.2013.12.021.

[18] H. I. Demir and H. Taskin, "Integrated Process Planning, Scheduling and Due-Date Assignment," $\mathrm{PhD}$ Thesis, Sakarya University, 2005.

[19] C. Erden and H. I. Demir, "Integrating process planning, scheduling and due date assignment in a dynamic environment," PhD Thesis, Sakarya University, 2019.

[20] H. I. Demir and C. Erden, "Solving process planning and weighted scheduling with WNOPPT weighted due-date assignment problem using some pure and hybrid meta-heuristics," Sakarya University Journal of Science, vol. 21, no. 2, pp. 210-222, 2017.

[21] H. I. Demir and C. Erden, "Dynamic integrated process planning, scheduling and due-date assignment using ant colony optimization," Computers \& Industrial Engineering, vol. 149, p. 106799, Nov. 2020, doi: 10.1016/j.cie.2020.106799.

[22] C. Erden, H. I. Demir, and A. H. Kökçam, "Solving Integrated Process Planning, Dynamic Scheduling, and Due Date Assignment Using Metaheuristic Algorithms," Mathematical Problems in Engineering, vol. 2019, 2019. 